Research Article

\title{
A Study on the Application of Two Different Material Constitutive Models Used in the FE Simulation of the Cyclic Plastic Behavior of a Steel Beam-Column T-Stub Connection
}

\author{
Wei Wang $\mathbb{D}^{1,2,3}$ Chenchen Zhang $\mathbb{D}^{1},{ }^{1}$ Zeshen Li $\mathbb{D},{ }^{1,2,3}$ and Xuehong Gan ${ }^{4}{ }^{4}$ \\ ${ }^{1}$ College of Civil Engineering, Shaoxing University, Shaoxing 312000, China \\ ${ }^{2}$ Key Laboratory of Rock Mechanics and Geohazards of Zhejiang Province, Shaoxing University, Shaoxing 312000, China \\ ${ }^{3}$ Zhejiang Collaborative Innovation Center for Prevention and Control of Mountain Geologic Hazards, Shaoxing University, \\ Shaoxing 312000, China \\ ${ }^{4}$ Department of Civil Engineering, Zhejiang College of Construction, Hangzhou 311231, China
}

Correspondence should be addressed to Zeshen Li; lizeshen@163.com

Received 8 October 2020; Revised 7 January 2021; Accepted 16 January 2021; Published 8 February 2021

Academic Editor: Raffaele Landolfo

Copyright (C) 2021 Wei Wang et al. This is an open access article distributed under the Creative Commons Attribution License, which permits unrestricted use, distribution, and reproduction in any medium, provided the original work is properly cited.

\begin{abstract}
Seismic actions inevitably cause cyclic plastic deformations in steel frame connections, which is a common cause of failure in steel structures. Nonlinear finite element (FE) static analysis has been employed in the study of the cyclic plastic behavior of a T-stub connection based on the reported cyclic test on the corresponding extensively tested T-stub connection made of Q235 steel. In particular, the isotropic-hardening and Chaboche constitutive models were employed to predict both the stress distribution and plastic development on the T-stub and the hysteretic curves of the entire T-stub connection. The two constitutive models were calibrated by four material tests to describe the yield and hardening behaviors of the Q235 steel used to make this T-stub connection. The two sets of simulation results obtained from the simulations of the two FE models employed by the two different constitutive models were compared with each other and with the experimental results. The comparisons reveal that the simulation results are similar and in good agreement with the experimental results when the cumulative plastic deformation in the T-stub is small. However, the results of the FE analysis using the Chaboche model are in better agreement with the experimental results when the cumulative deformation in the T-sub is large. This study can provide a reference for FE simulation of the cyclic plastic behavior of steel connections, including the T-stub connection.
\end{abstract}

\section{Introduction}

In steel frame structures, beam-column connections are important and diverse. When an earthquake occurs, the failure of the beam-column connections directly lead to the failure of the entire structure, thus causing casualties and damage of properties $[1,2]$. T-stub connection, which belongs to the semi-rigid type of connection, is a common connection type with a simple mechanism, clear forcetransmission path, and a convenient method of construction [3]. Previous experimental studies have shown that T-stub connections have a better seismic performance than the traditional welded one $[4,5]$. Also, among all types of semirigid connections, $\mathrm{T}$-stub connection has the highest bending capacity. Therefore, T-stub connections have a broad application prospect.

Numerous studies have been carried out on the static performance of T-stub connections such as the total performance [5-7] and the local performance [4, 8-16]. Most of the studies on the total and local performances of T-stub connections were carried out by the finite element (FE) method, and the reason is that most of the phenomena such as the development of plastic behavior of the T-stub cannot be observed visually via experimental methods [8]. Tartaglia et al. used the FE method to analyze the internal forces developed in the flange and the bolt shank of the T-stub specimen, and to investigate the influence of distance between the bolts and the transverse edge of flange and some 
constructional imperfections on the T-stub behavior [9]. For the two European systems of high strength preloadable bolts adopted in steel-structural connections such as T-stub connections, D'Aniello et al. proposed some simplified criteria for FE modeling, and the comparison between EC3 analytical and FE numerical models of T-stubs was made, based on which some criticisms of the EC3 analytical prediction of the T-stub response were made [10]. Faralli et al. used the finite element method to assess the influence of second-order effects on the deformation capacity of T-stubs bolted to a rigid support through a parametric investigation [11]. On the FE simulation of the overall or local performance of the T-stub connections, there are lots of other studies such as those reported by [13-15]. Thus, the FE method is an important technique to study the static performance of T-stub connections.

FE simulations of the static behavior of such structures as the T-stub connections can be narrowed down to solving a set of nonlinear equations only constructed by externally applied nodal force $\mathbf{f}$ and internal equivalent nodal force $\mathbf{p}$. The accuracy of the simulation results strongly depends on the employed constitutive model of the integration points in elements, which is used to calculate $\mathbf{p} 1$ [17]. The constitutive model of structural steels can generally be described by the incremental classical plastic theory, which is jointly defined by a yield criterion, a criterion for plastic loading and unloading, a strengthening rule, and a plastic flow rule [18]. The strengthening rules can be divided into isotropic, kinematic, and combined hardening, according to the variation of the size, shape, and position of the plastic loading surface [18]. Regardless of the kind of strengthen rule adopted, when the classical plastic theory is used to determine the constitutive relationship of an integration point, an updating algorithm of the constitutive status is needed, in which a tensor differential equation containing the hardening modulus is solved [18]. Compared with a combined hardening constitutive model, the computation of the hardening modulus of an isotropic-hardening constitutive model (IHM) is much less [18]. Moreover, when IHM is adopted, the material stiffness matrix, which must be used when performing FE simulations, can be obtained without matrix inversion calculations, and this phenomenon can greatly improve the calculation speed of the FE program [19]. As a result, IHM is widely used in FE simulations of steel connections under cyclic loading [6-8, 12-14].

Generally, there are large cyclic plastic areas in a T-stub connection of a steel building when it suffers a large horizontal reciprocating motion caused by a large earthquake. One of the main reasons for structural failure is the cyclic plastic deformation in the steel connections, which cannot be described by IHM [20]. Therefore, it is necessary to choose a constitutive model that can accurately describe the mechanical behavior of metals under cyclic plastic loading to ensure high FE simulation accuracy of the behavior of the T-stub connections.

Chaboche constitutive model (CHM) can capture the cyclic mechanical behaviors of metals (like Q235 steel for T-stub connections) such as cyclic hardening, Bauschinger effect, ratcheting behavior, and mean stress relaxation [21].
The reliability and superiority of CHM have been confirmed by various experimental tests on the cyclic mechanical behavior of metals [22-24], and it is implemented in many commercial FE software. Badnava et al. [22] used CHM to predict the ratcheting effect of circular steel pipes under the cyclic combined action of internal pressure in the pipe. Shojaei et al. [23] also used the CHM to predict the ratcheting effect of stainless-steel beams under cyclic loading. The model was also employed by Mancini et al. [24] to predict the cyclic plastic behavior of a three-layer aluminum frame under the motion of the base. The results obtained from the above studies are satisfactory. However, there are few reports on the application of CHM in the prediction of the cyclic plastic behaviors of T-stub connections under cyclic loading. There may be two reasons for this. On the one hand, CHM has more parameters to be determined (see Section 2.3), and the calibration of these parameters requires several material cyclic loading tests [25]. On the other hand, compared with IHM, CHM is more complicated and, therefore, a higher computational cost is required when it is used to update the constitutive state of an integration point [19]. However, based on the superiority of $\mathrm{CHM}$, as mentioned in the above investigations, it is necessary to study the differences in the prediction results of the cyclic plastic behavior of T-stub connections obtained using CHM and IHM.

Based on a reported pseudo-static test of T-stub connection made of Q235 steel [26], the nonlinear static behaviors of the two connections whose constitutive model is CHM and IHM, respectively, were studied with the help of the ABAQUS code. In this study, first, four material tests were completed, and the material of the specimens in these tests was the same as the one used for manufacturing the abovementioned T-stub connection. Then the constitutive parameters of CHM and IHM for the steel were calibrated accordingly. Next, the FE model of the T-stub connection was developed using Abaqus/CAE. Finally, Abaqus/Standard was adopted to complete the FE implicit static analyses. This study shows that the simulation results obtained using the two constitutive models are similar and in agreement with the experimental results when the cumulative plastic deformation is small, but the results obtained using CHM are in better agreement with the experimental results when the plastic deformation is large.

The structure of this paper is as follows: The mathematical expressions of CHM and IHM, as well as the tests, methods, and results of the calibration of the parameters of the two constitutive models, are described in Section 2. In Section 3, a T-stub connection, which had been extensively tested with a cyclic loading scheme, is described firstly, followed by a detailed description of the corresponding FE model. The experimental and simulation results of this T-stub connection are given in Section 4, and the conclusion is given in Section 5.

\section{Material Behavior}

In this section, the two constitutive models employed in the simulation of the cyclic plastic behavior of the really tested 
T-stub connection are described. Then, the schemes and results of the uniaxial tensile and cyclic loading tests used to calibrate the constitutive parameters are discussed briefly. Finally, the calibration method for CHM and the calibration results for the two models are presented.

2.1. Constitutive Models. The constitutive equation (rate form) given by the classical plastic constitutive theory can be written as $\dot{\sigma}=\mathbf{D}: \dot{\varepsilon}$, where $\sigma$ is the stress tensor, $\mathbf{D}$ is the material stiffness tensor, $\varepsilon$ is the strain tensor, $\cdot$ represents the rate form of variable, and ":" is the double dot product for two tensors. The value of $\mathbf{D}$ depends on the material status defined by the yield function $f$, which also defines the law of development of the yield surface. The constitutive characteristic of a material is elastic if $f<0$, and under this condition, $\mathbf{D}$ equals the elastic stiffness matrix $\mathbf{D}_{e}$, which is a function of elastic modulus $E$ and Poisson's ratio $v$ when the material is isotropic. If $f=0$, the constitutive characteristic of the material is plastic, and under this condition, $\mathbf{D}$ equals the elastoplastic stiffness matrix $\mathbf{D}_{e p}$, which is determined by the yield function, plastic flow rule, and consistency condition constructed by the yield function [27]. Generally $[28,29]$, the type of associated plastic flow rule is chosen at a condition where the rate of plastic strain tensor $\varepsilon_{p}$ can be expressed as $\dot{\varepsilon}_{p}=\dot{\lambda}(\partial f / \partial \sigma)$, where $\lambda$ is the consistency parameter. Also, for metallic material, $f$ is often constructed based on the Mises material model, in which $\dot{\lambda}$ can be given by the Prandtl-Reuss equation. Therefore, when CHM and IHM are adopted to describe the constitutive relationships of the metallic materials used for making T-stub connections, it is key to determine the mathematical form of the yield function $f$ based on the Mises model.

2.1.1. The Yield Function of the Chaboche Model. The yield function $f$ of CHM can describe the expansion and translation of yield surface, and when equivalent Mises stress is used, $f$ can be written as [30]

$$
f(\boldsymbol{\sigma}, \boldsymbol{\alpha}, k)=\left[\frac{3}{2}\left(\mathbf{s}_{\boldsymbol{\sigma}}-\mathbf{s}_{\boldsymbol{\alpha}}\right):\left(\mathbf{s}_{\boldsymbol{\sigma}}-\mathbf{s}_{\boldsymbol{\alpha}}\right)\right]^{0.5}-k(\boldsymbol{\kappa})=0,
$$

where $\alpha$ is the back-stress tensor defining the central coordinate of yielded surface; $\mathbf{s}_{\alpha}$ is the deviatoric part of $\alpha$, which can be expressed as $\mathbf{s}_{\alpha}=\alpha-(1 / 3) \operatorname{tr}(\alpha) \mathbf{I}(\operatorname{tr}(\cdot)$ is the trace operation and $\mathbf{I}$ is the unit tensor). $\mathbf{s}_{\sigma}$ is the deviatoric stress tensor, which can be written as $\mathbf{s}_{\sigma}=\sigma-(1 / 3) \operatorname{tr}(\sigma) \mathbf{I}$. $k(\kappa)$ is the hardening function that defines the size of the yielded surface, where $\kappa$ is the hardening parameter vector. Usually, the hardening function can be modeled thus [30]

$$
k(\boldsymbol{\kappa})=\sigma_{y, 0}+Q\left[1-\exp \left(-b \varepsilon_{e p}\right)\right],
$$

where $\varepsilon_{e p}$ is the equivalent plastic strain, $\sigma_{y, 0}$ is the size of the yielded surface when $\varepsilon_{e p}=0, Q$ is the maximum value of the radius increment of the yielded surface, and $b$ is the changing rate of the radius increment of the yielded surface with plastic strain. In order to improve simulation accuracy, the overall back-stress tensor $\alpha$ can be computed from the relation,

$$
\boldsymbol{\alpha}=\sum_{j=1}^{N} \boldsymbol{\alpha}_{j}
$$

where $\alpha_{j}$ is the $j$ th back-stress component, and $N$ is the number of components. It is generally believed that $\alpha$ only depends on the two field variables, $\sigma$ and $\varepsilon_{e p}$, and the evolution rule of the component, $\alpha_{j}$, is defined as [30]

$$
\dot{\alpha}_{j}=\frac{C_{j}}{k}\left(\boldsymbol{\sigma}-\boldsymbol{\alpha}_{j}\right) \dot{\varepsilon}_{e p}-\gamma_{j} \boldsymbol{\alpha}_{j} \dot{\varepsilon}_{e p},
$$

where $C_{j}$ is the initial kinematic hardening modulus, and $\gamma_{j}$ is the parameter that determines the changing rate of the kinematic hardening modulus.

In this study, $k(\kappa)$ and $\alpha$ were constructed by calibrating $\sigma_{y, 0}, Q$, and $b$ in (2) as well as $C_{j}$ and $\gamma_{j}$ in (3) based on the results of material tests. Thus, the yield function $f$ in (1) can be obtained. In addition, two back-stress components were used to construct $\alpha$; hence, $N$ in (3) equals 2 .

\subsubsection{The Yield Function of the Selected Isotropic-Hardening} Model. The yield function $f$ of IHM can only capture the expansion of the yielded surface, and when equivalent Mises stress is used, $f$ can be expressed as [18]

$$
f(\boldsymbol{\sigma}, k)=\left[\frac{3}{2} \mathbf{s}_{\mathbf{\sigma}}: \mathbf{s}_{\boldsymbol{\sigma}}\right]^{0.5}-k(\boldsymbol{\kappa})=0,
$$

where $k$ is the initial or subsequent yield stress, whose independent variable $\kappa$ is scalar and is often replaced by the plastic strain $\varepsilon_{p}$. Thus,

$$
k(\boldsymbol{\kappa})=k\left(\varepsilon_{p}\right) .
$$

A series of points are captured to construct the $k-\varepsilon_{p}$ relationship in the above formula by a uniaxial tensile test [18], which is adopted by Abaqus [30].

\subsection{Experimental Tests on Specimens for Material Model} Calibration. The mechanical behavior of the specimens, which were fabricated from the flange part of the mother structural steel used in making the T-stub connections reported in [26], was determined in this study, and the data acquired from these tests were used to calibrate the parameters of the CHM and IHM. The geometries and dimensions of all the tested specimens are shown in Figure 1, which also gives a real picture of a specimen. There are two different parts for each specimen: the cylindrical part with a smaller diameter in the middle, which is the test target region, and the part with a bigger diameter at both ends, the clamped regions.

The axial monotonic tensile and axial cyclic loading tests were performed at room temperature to obtain the deformation behavior of Q235 steel using a MTS809 tensile and torsional fatigue testing machine. The test setup is shown in Figure 2. Prior to the test, the specimens were clamped between the grips of the test machine. An extensometer with a gage length of $25 \mathrm{~mm}$ (see Figure 2) was installed in the middle of each specimen to accurately measure the average 


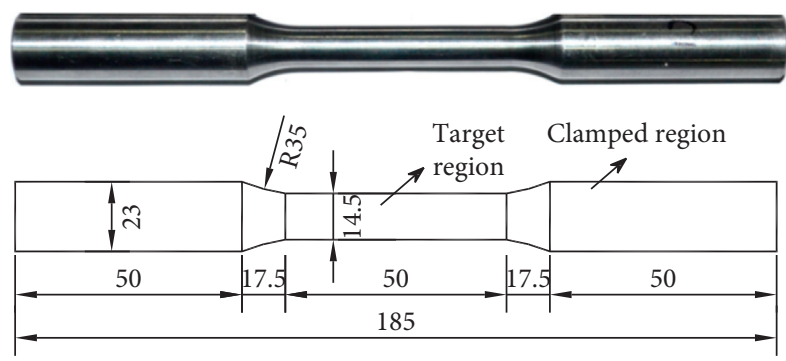

FIGURE 1: Geometry and dimensions of the material specimen (in $\mathrm{mm})$.

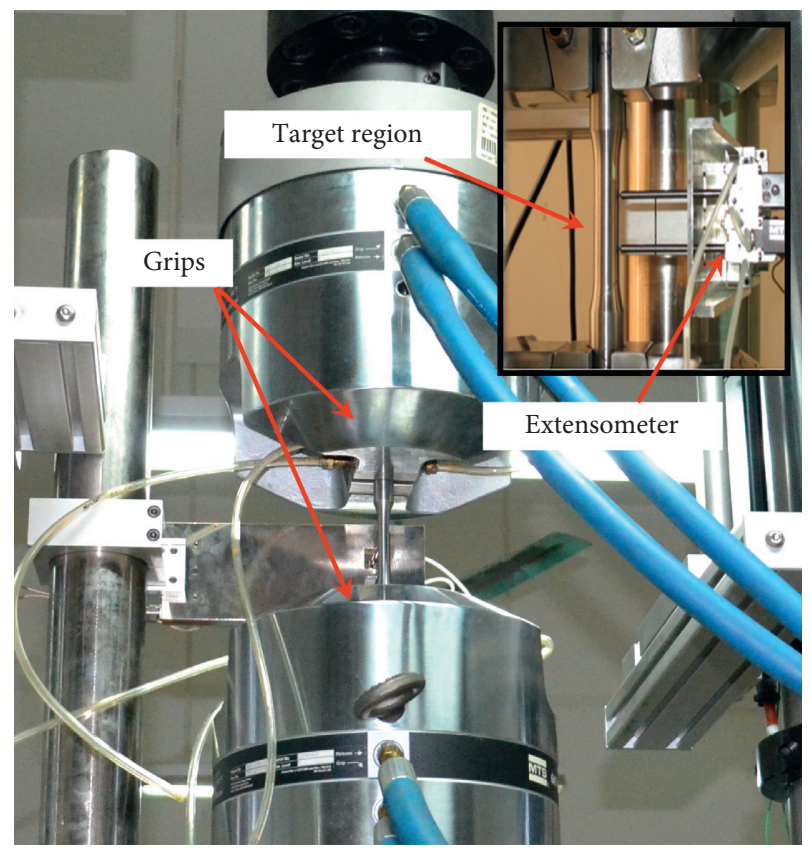

Figure 2: Test setup for the study of the material behavior.

strain during the loading process. A scheme of straincontrolled loading was used in the test, and the loading frequency was set to $0.02 \mathrm{~Hz}$. The value of the stress can be calculated by dividing the axial load by the cross-sectional area of the measured region. A total of four axial loading tests were performed. Three of the tests were axial cyclic loading tests, and each of them was terminated when a stable hysteresis curve appeared. To improve the accuracy of the parameter calibration, three different strain amplitudes $(0.002,0.005$, and 0.01$)$ were selected, and only one hysteresis loop was drawn under each strain amplitude because the hysteresis loops under the same amplitude were very consistent. The obtained $\sigma-\varepsilon$ curves are shown in Figure 3 . The fourth test was a uniaxial tensile test, which was terminated at a tensile strain of 0.15 . The $\sigma-\varepsilon$ curve obtained in this test is shown in Figure 4.

2.3. Model Calibration. The parameters of CHM and IHM were calibrated based on the methods for constructing the hardening function $k(\kappa)$ mentioned in Section 2.1 and the material test results for the Q235 steel in Section 2.2. The

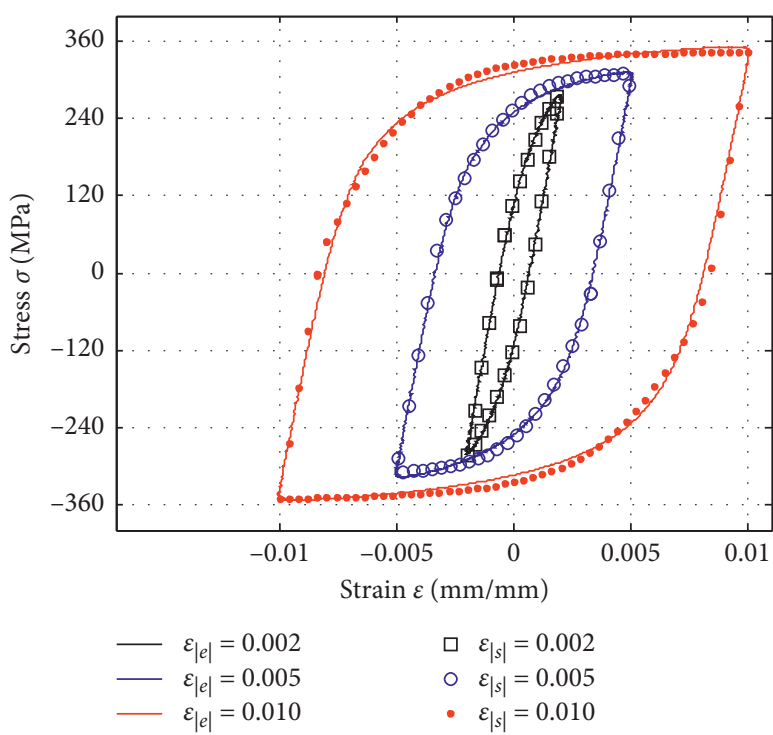

FIgURE 3: Experimental and simulation $\sigma-\varepsilon$ curves under uniaxial loading at different strain amplitudes for Q235 steel. Note: $\varepsilon$ is the value of strain amplitude when did, and that taking $e$ denotes experiment and taking $s$ denotes simulation.

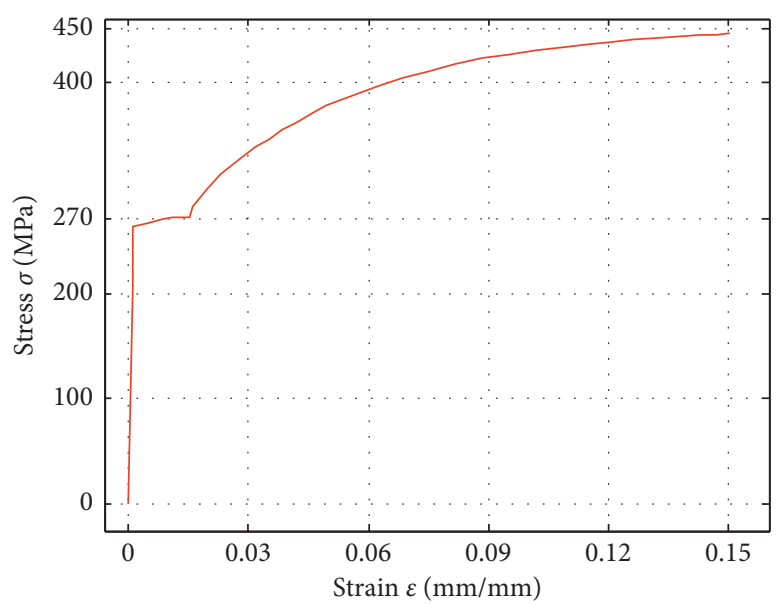

FIgURE 4: Experimental $\sigma-\varepsilon$ curve under uniaxial tension for Q235 steel.

parameters of $\mathrm{CHM}$ were determined with reference to the $\sigma-\varepsilon$ experimental curves in Figure 3 and with the help of the parametric identification method described in [25]. The obtained parameters for CHM are summarized in Table 1. Using these parameters and with the same loading scheme mentioned in Section 2.2, the $\sigma-\varepsilon$ curves obtained from the FE simulation with only one element are also shown in Figure 3. It can be observed from the figure that the FEpredicted curves are in good agreement with the experimental results. The key parameter of IHM, which is the $k-$ $\varepsilon_{p}$ data mentioned in Section 2.1.2, was determined by the uniaxial tensile test. Several samples of the $k-\varepsilon_{p}$ data are listed in Table 2. Thus, the hardening function, $k(\kappa)$, can be constructed using the parameters in Table 1 for CHM or the data in Table 2 for IHM during FE simulations of the cyclic plastic behavior of the reported $\mathrm{T}$-stub connection. 
TABLE 1: Material parameters of Chaboche constitutive model for Q235 steel.

\begin{tabular}{|c|c|c|c|c|c|c|c|c|}
\hline Steel type & $E(\mathrm{GPa})$ & $\sigma_{y, 0}(\mathrm{MPa})$ & $Q(\mathrm{MPa})$ & $b$ & $c_{1}(\mathrm{GPa})$ & $\gamma_{1}$ & $c_{2}(\mathrm{GPa})$ & $\gamma_{2}$ \\
\hline Q235 & 202000 & 270 & 200 & 40 & 2700 & 40 & 800 & 50 \\
\hline
\end{tabular}

TABLE 2: $k-\varepsilon_{p}$ experimental data for Q235 steel.

\begin{tabular}{lc}
\hline$k(\mathrm{MPa})$ & $\varepsilon_{p}$ \\
\hline 270.000 & 0.000 \\
324.510 & 0.018 \\
386.250 & 0.047 \\
440.250 & 0.118 \\
445.000 & 0.150 \\
\hline
\end{tabular}

\section{T-Stub Connection's Cyclic Loading Test and FE Model}

3.1. Test Introduction. The details of the cyclic loading test of the T-stub connection whose behavior was simulated in this study can be found in the literature [26]. The column and the beam were made of standard Q235 H-shaped steel. The T-stubs were obtained by cutting the same kind of $\mathrm{H}$-shaped steel. Grade 10.9 frictional-type high-strength bolts were used to connect the column and the beam. The geometric dimensions of the entire connection and those of the crosssections are shown in Figure 5. Figure 6 shows the detailed dimensions of the T-stubs. The diameter of the bolt holes in both the top T-stub $\left(T_{\mathrm{t}}\right)$ and the bottom T-stub $\left(T_{\mathrm{b}}\right)$ was $22 \mathrm{~mm}$. A uniaxial tensile test was conducted to obtain the stress-plastic strain $\left(k-\varepsilon_{p}\right)$ curve of the steel designated as 40CR used for making the bolt assemblies, which is shown in Table 3. It must be stated that the failure mode of the type of T-stubs $\left(T_{t}\right.$ and $\left.T_{b}\right)$ can be estimated according to the mechanical and geometrical features of it and to the failure description and criteria given in Sub-section 2.1 of [9], and the estimated result is illustrated by Figure 7 in which the colored regions with red are plastic ones under large deformations.

The test setup is shown in Figure 8. The upper end of the column was horizontally restrained by a reaction shear-wall, and the lower end was fixed to a base. The vertical displacement $\Delta$ and vertical load $P$ at the load-applied end of the beam were measured by an electronic displacement meter and a force sensor on the actuator, respectively. During the test, a displacement control scheme was adopted to apply cyclic loads, and the sequence assembled by the absolute values of the controlled displacements can be remarked as $\mathbf{d}_{\text {con }}=\left\{d_{1}, d_{2}, d_{3}, \ldots, d_{i}, \ldots\right\}$, where $d_{i}$ is the absolute value of the controlled displacement in the $i$ th load level. When $i \leq 3, d_{1}=2 \mathrm{~mm}, d_{2}=4 \mathrm{~mm}$, and $d_{3}=5 \mathrm{~mm}$, and $d_{i}=(5+5(i-3)) \mathrm{mm}$ while $i>3$.

When the test started, but before the first cyclic load was imposed, a vertical load was applied to the top of the column at a design axial compression ratio of 0.2 . When this step finished, the other cyclic loads were imposed level by level, and the load in each level began in a downward direction, which was defined as positive, and cycled 3 times (see Figures 5 and 8 for more information). The test was terminated when the maximum load at a single level dropped to

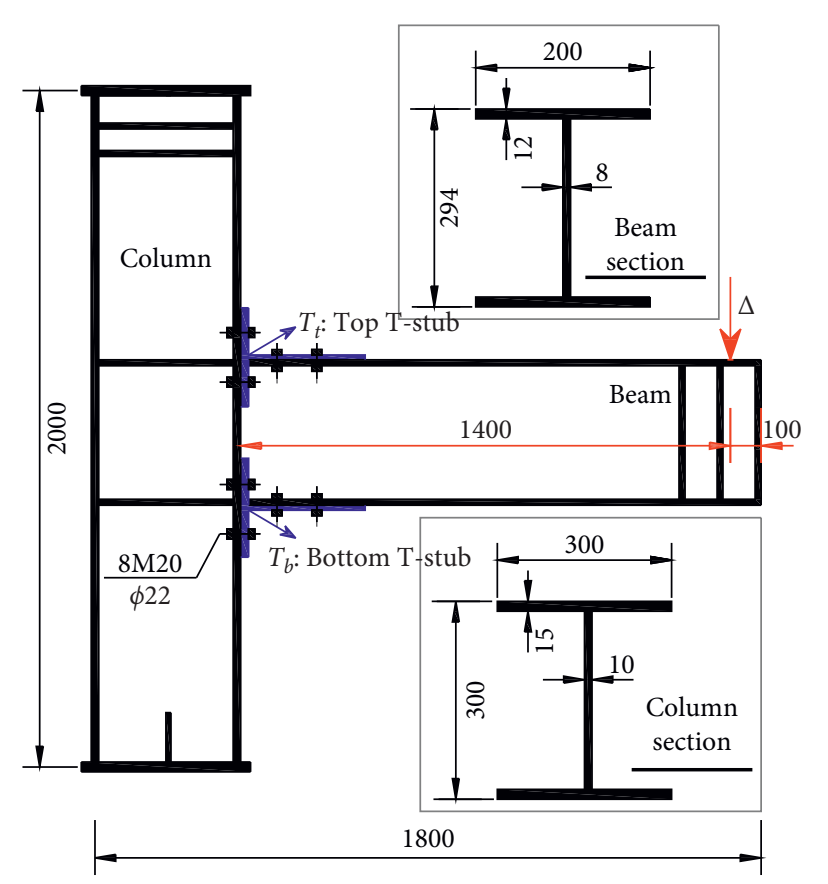

FIgURE 5: Geometry, dimensions, and loading point of the T-stub connection (in $\mathrm{mm}$ ).
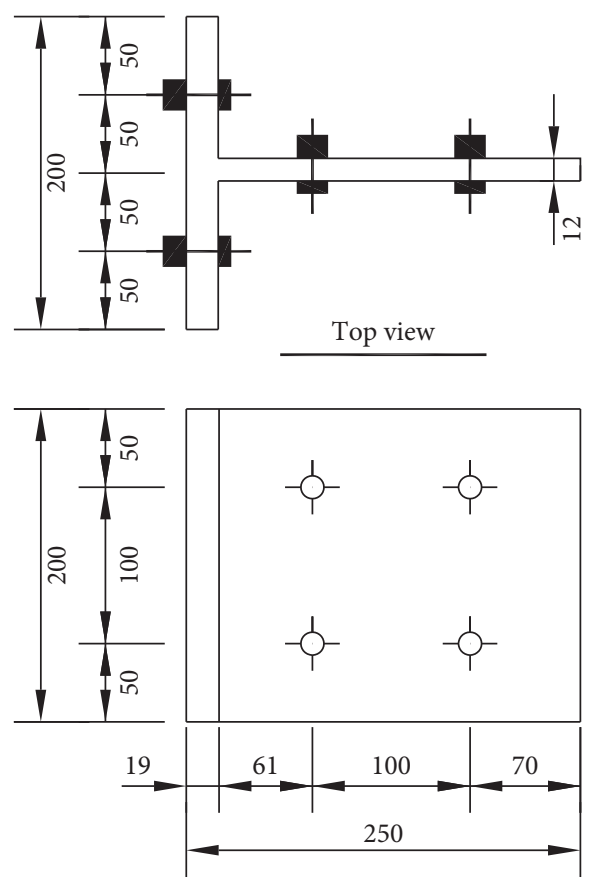

Sectional view

Figure 6: Geometry and dimensions of the T-stub (in mm).

$85 \%$ of the ultimate load in all the levels. It should be noted that the vertical actuator must be adjusted in real-time to 
TABLe 3: $k-\varepsilon_{p}$ experimental data for $40 \mathrm{CR}$ steel.

\begin{tabular}{lc}
\hline$k(\mathrm{MPa})$ & $\varepsilon_{p}$ \\
\hline 1063.90 & 0.000 \\
1079.89 & 0.010 \\
1086.45 & 0.013 \\
1099.10 & 0.024 \\
1107.89 & 0.041 \\
\hline
\end{tabular}

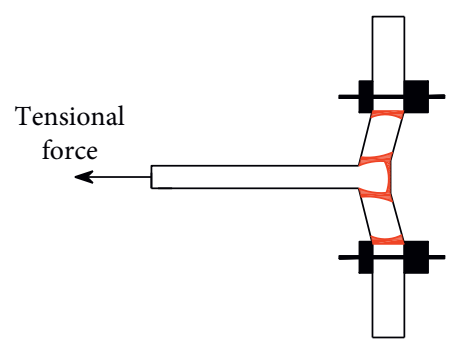

Figure 7: The estimated failure mode of T-stub by analytical method.

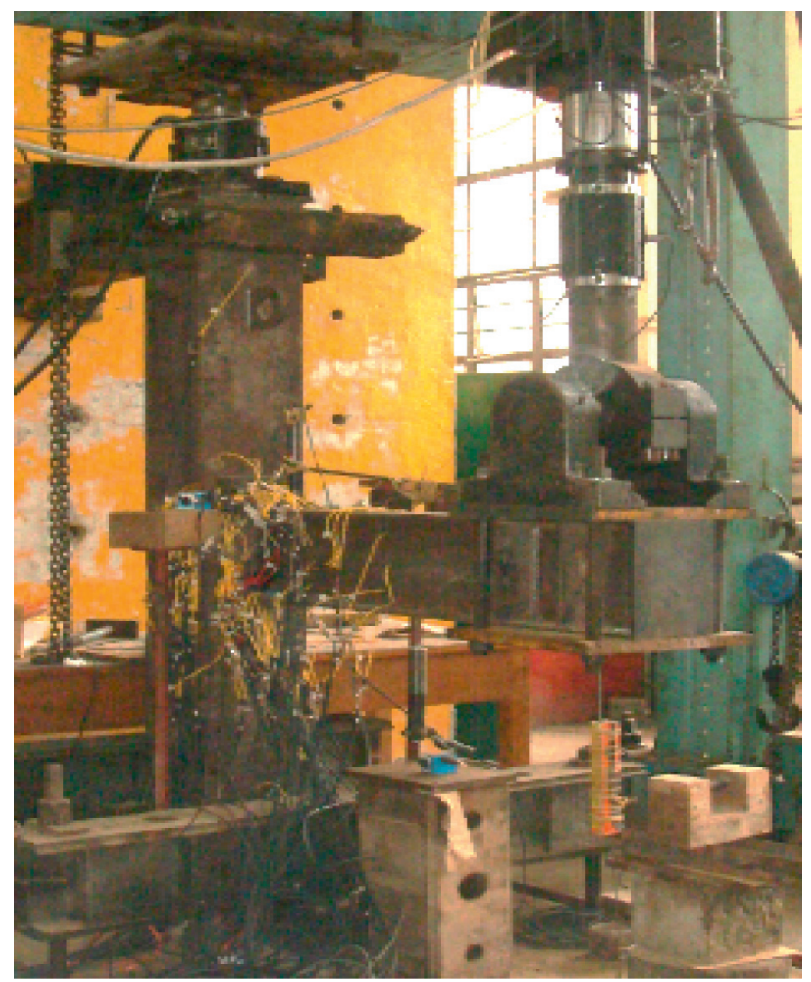

Figure 8: Test setup of T-stub connection for static behavior.

keep the axial pressure ratio constant all through the loading process. Finally, the load-displacement $(P-\Delta)$ curve at the load-applied point was obtained, which is described in detail in Section 4.2 of this paper (see [26] for more test results such as failure process and strain distribution).

3.2. FE Model. Because the T-stub connection is symmetrical about the longitudinal plane through the center of the beam web (see Figure 9(a)), only half of it was established using the ABAQUS software, as illustrated in Figure 9(b).
The boundary conditions and loading scheme for the FE model were in accordance with those for the really tested model, as described in Section 3.1. In addition, the displacement of the nodes of the element lying on the symmetrical plane, see $S_{s}$ in Figure 9(a), was constrained along the normal direction of $S_{s}$. A solid element designated as C3D8I in the ABAQUS library of elements was adopted to discrete the geometry of the T-stub connection. Generally, the sweeping method was utilized to automatically complete the discretization, but the area of the connection core and its neighborhood, where the stress status was more complex than other areas, were manually refined by elements with smaller dimensions. The final discrete FE model is illustrated in Figure 9(c). Based on the geometry and boundary conditions of the really tested $\mathrm{T}$-stub connection, two FE models were developed. The constitutive models for the three main components of the models (T-stubs, column, and beam) adopted the CHM whose parameters are shown in Table 1 and IHM whose parameters are shown in Table 2.

The FE modeling methods of bolt assembly stated in [6] were adopted to develop the FE models of the type of bolt assemblies used in the studied connection. Each blot assembly can be seen as a single continuous element composed of two zones, namely, Zone 1 and Zone 2, as shown in Figure 10(a). Zone 1 corresponds to bolt head and nut, while Zone 2 corresponds to the shank. The dimensions of these components are shown in Figure 10(b), and the value in the bracket is the shank height of bolts in the flanges of T-stubs, which is different from the bolts in the webs of the T-stubs, which are equal to $22 \mathrm{~mm}$. The sweeping method was also utilized to complete the discretization with the same type of element, C3D8I, and Figure 10(a) shows the result. The bolt assemblies were made of $40 \mathrm{CR}$ steel, and no matter which FE model of connection a bolt assembly belongs to, it adopted IHM with $E=202 \mathrm{GPa}$ and a Poisson coefficient of $v=0.3$. This IHM was calibrated on the basis of a corresponding monotonic test, and Table 3 shows its constitutive parameters. In accordance with the test scheme, a preloaded internal tensional force equaling to $155 \mathrm{kN}$ was added to the shank before loading at the end of beam, and during the loading, the height of shank was controlled as a constant in which condition the internal tensional force varied.

All the contact surfaces in the FE model, as shown in Figure 9(d), were modeled according to the real-life conditions. There were both compression effects in the normal direction and frictional effect in the tangential direction between the contact surfaces of the T-stub and the beam/column $S_{1, c s}$ in Figure 9(d) and that between the bolt/nut and the T-stub/beam/ column $S_{2, c s}$ in Figure 9(d). Therefore, a combination was set with a hard contact mode to simulate the normal contact behavior and a Coulomb frictional mode to simulate the tangential contact behavior. The frictional coefficient of the Coulomb frictional mode was set to 0.4 . There is a normal pressive effect mainly between the bolt shank and the bolt holes; therefore, only the hard contact mode was adopted. Loads were applied in two steps in the simulation. The first step involved the preloading of the bolt, and the second involved the application of the cyclic loads level by level. Both steps must be in accordance with the test scheme. The simulation results are detailed in Section 4 . 


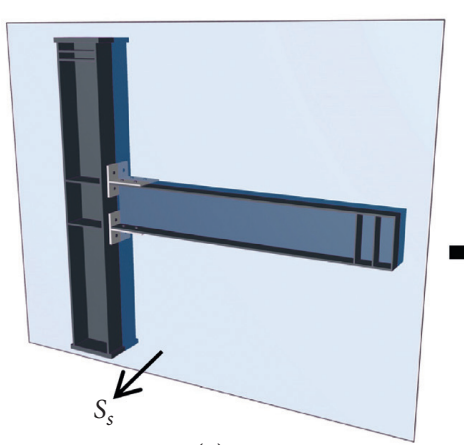

(a)

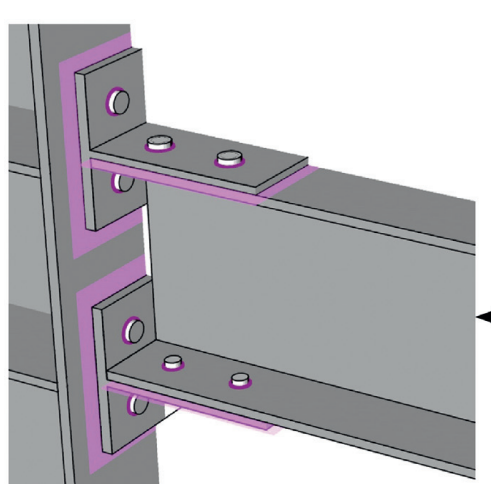

(d)

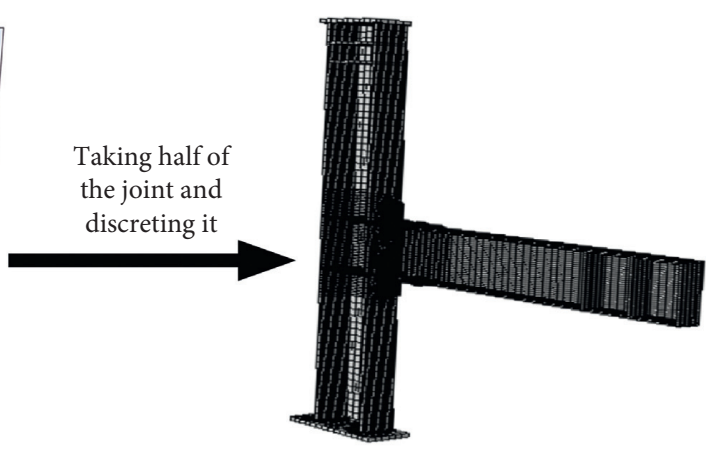

(b)

Refining the core areas

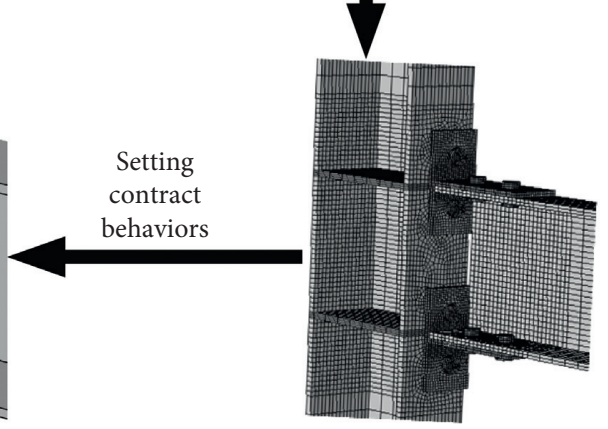

(c)

$S_{1, c s}$

FIgURE 9: The finite element modeling of T-stub connection. Note: $S_{s}$ is the symmetry plane of the connection; $S_{1, c s}$ the contact surfaces between the T-stub and the beam/column; $S_{2, c s}$ the contact surfaces between the nut and the T-stub/beam/column.

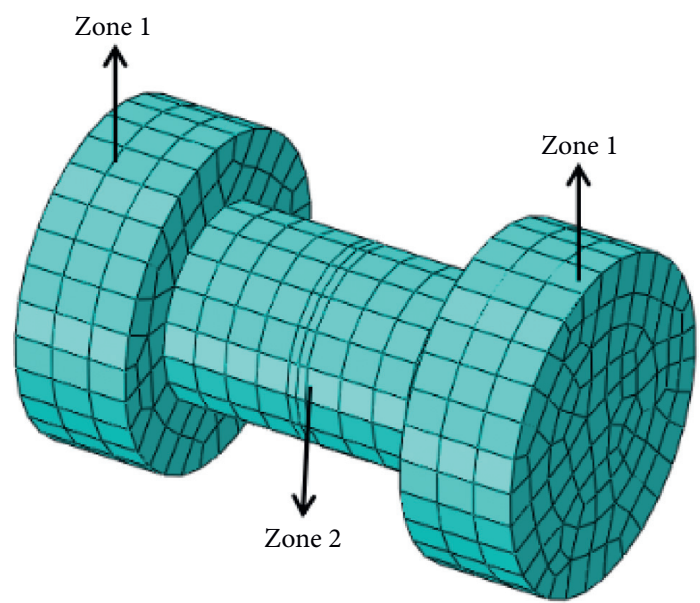

(a)

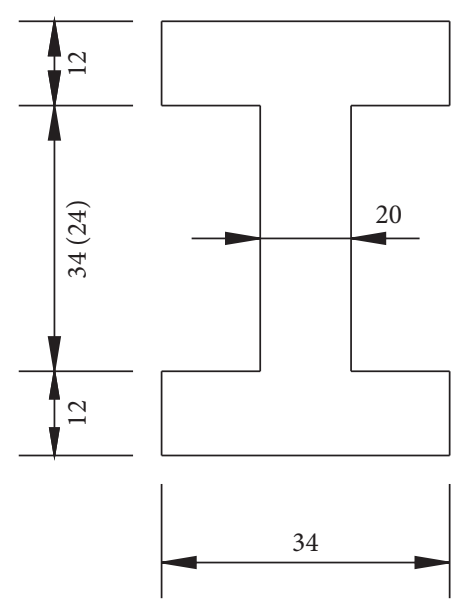

(b)

FIGURE 10: Components and dimensions of the FE geometry model of the bolt assembly. (a) Components. (b) Dimensions (in mm).

\section{Numerical Simulation Results and Discussion}

In this section, by the CHM-S and IHM-S, the simulation results, including the distributions of the Mises stress $\sigma_{m i}$ and equivalent plastic strain $\varepsilon_{e p}$ of the upper T-stub $\left(T_{t}\right)$, and the load-displacement $(P-\Delta)$ curves at the load-applied point are presented and discussed. Herein, the abbreviation CHM-S represents the simulation work on the FE model copy that adopted the Chaboche constitutive model, and IHM-S represents that on the other copy that adopted the isotropic-hardening constitutive model. 
4.1. $\sigma_{m i}$ and $\varepsilon_{e p}$ of $T_{t}$. It has been pointed out that the cyclic plastic behavior of $\mathrm{T}$-stubs greatly affects the overall cyclic plastic behavior of a T-stub connection $[3,4]$. Both the Mises stress $\sigma_{m i}$ and the equivalent plastic strain rate $\dot{\varepsilon}_{e p}=\left((2 / 3) \dot{\mathcal{\varepsilon}}^{p}: \dot{\mathcal{\varepsilon}}^{p}\right)^{(1 / 2)}$, where $\dot{\mathcal{\varepsilon}}^{p}$ is the plastic strain rate, are two important parameters to determine the degree of a material point in a plastic status under a complex stress condition. It was found that the two simulation results, $\sigma_{m i}$ and $\varepsilon_{e p}$, depend on the constitutive model employed, and the behavior of the upper T-stub, $T_{t}$, of the connection is extremely similar to that of the lower T-stub under cyclic loading. Therefore, only the $T_{t}$ component in each FE model was considered in the illustration of the $\sigma_{m i}$ and $\varepsilon_{e p}$ at different loading levels. Considering the CHM-S and IHM-S, the obtained results were different, as well as the evidence which was used to demonstrate the other results showed in Sections 4.2 and 4.3 was obtained.

4.1.1. Mises Stress $\sigma_{m i}$ of $T_{t}$. Some $\sigma_{m i}$ contour plots selected as the representatives of $T_{t}$ are presented in Figure 11; the subfigures on the left column are those obtained from IHMS when the displacement is $\Delta_{1 \mathrm{st},+} \in \mathbf{d}_{\text {con }}=\{5,20,40,60\} \mathrm{mm}$ and those on the right column, except the one at the top, are those obtained from CHM-S when $\Delta_{1 \mathrm{st},+} \in \mathbf{d}_{\text {con }}=$ $\{20,40,60\} \mathrm{mm}$. Herein, $\Delta_{1 \mathrm{st},+}$ denotes the positive displacement of the load-applied point which first reaches the controlled displacement in each loading level. The color bar that shows the color scale of the stress contour plots is also shown in Figure 11.

It can be observed from the subfigures in Figure 11 that the distribution and diffusion of $\sigma_{m i}$ given by CHM-S were similar in quality to those obtained from IHM-S. The stress at the geometric discontinuities, such as the bolt holes and web flange junctions, varied drastically, whereas it changed smoothly at the continuous areas far from the discontinuities. Both phenomena are consistent with the Saint Venant's principle. The areas to be yielded $\left(\sigma_{m i} \geq 270 \mathrm{MPa}\right)$ increased with the increase in $\Delta_{1 s t,+}$, and before $\Delta_{1 s t,+}$ first reached $60 \mathrm{~mm}$, most areas of the T-stub had yielded.

However, there are obvious quantitative differences between the $\sigma_{m i}$ given by IHM-S and that from CHM-S when $\Delta_{1 \text { st, }+}$ reaches a large $d_{\text {con }}$. It can be observed from Figure 11 that the color-value of $\sigma_{m i}$ at the geometric discontinuities determined by CHM-S is significantly larger than that of IHM-S when $\Delta_{1 \mathrm{st},+}=d_{\text {con }} \geq 40 \mathrm{~mm}$ and especially when $\Delta_{1 s t,+}=60 \mathrm{~mm}$. This quantified difference in $\sigma_{m i}$ indicates the quantified difference in the degree of plastic development given by IHM-S and CHM-S, which will be further discussed in Section 4.1.2.

4.1.2. Equivalent Plastic Strain $\varepsilon_{e p}$ of $T_{t}$. Along four typical paths at $T_{t}$, the corresponding four areas were chosen to analyze the plastic development behavior. These four paths, which are named as $l_{1}, l_{2}, l_{3}$, and $l_{4}$, respectively, are shown in Figure 12 . They are accurately positioned by a Cartesian coordinate system, $x y z$. The $x o z$ plane on this system coincides with the flange surface $S_{F}$, whereas the xoy plane coincides with the stem surface $S_{W}$. The intersection line between $S_{W}$ and $S_{F}$ is designated as $l_{0}$, and each of the $l_{1}, l_{2}, l_{3}$, and $l_{4}$ is parallel to $l_{0}$. The two typical paths, $l_{1}$ and $l_{2}$, are located on $S_{F}$, whereas $l_{3}$ and $l_{4}$ are on $S_{w}$. The distances from $l_{0}$ to $l_{1}, l_{2}, l_{3}$, and $l_{4}$ are $16,4,4$, and $16 \mathrm{~mm}$, respectively. The $\varepsilon_{e p}$ on each path when $\Delta_{1 \text { st },+} \in \mathbf{d}_{\text {con }}=\{5,10,20,40,60\}$ is shown by the $x-\varepsilon_{e p}$ curve in Figure 13, where $x$ is the $x$-coordinate value of a point on the path. On the legends of the $x-\varepsilon_{e p}$ curves, $\Delta_{\mathrm{I}}$ and $\Delta_{\mathrm{C}}$ indicate the displacements obtained in IHM-Sand CHM-S, respectively, and the values without dimensional units are the magnitude of the displacements. Here, it is worthy of note that although there are nonzero values on the $x-\varepsilon_{e p}$ curve for path $l_{2}$ when $\Delta_{1 \text { st, }+}=10$, the curve cannot be plotted in Figure 13(b) normally because the $\varepsilon_{e p}$ values on the curve are much smaller than those on other curves of this same subfigure.

It is perceptually obvious that the plastic behavior of $T_{t}$, from the $x-\varepsilon_{e p}$ curves in Figure 13 obtained from CHM-S is similar to those deduced from the curves obtained from IHM-S. From the $x-\varepsilon_{e p}$ curves of $l_{1}$ and $l_{2}$ or $l_{3}$ and $l_{4}$, it is found that, at the same loading level, the farther away from $l_{0}$, the lower the degree of plastic development. On the same path, according to the subplots of Figure 13, it can also be concluded that the higher the loading level, the greater the degree of plastic development. For a given $x$ and $\Delta_{1 s t,+}$ higher than $20 \mathrm{~mm}, \varepsilon_{e p}$ on the path $l_{2}$ is much greater than that on path $l_{1}$, and $\varepsilon_{e p}$ on the path $l_{3}$ is much greater than that on the path $l_{4}$. The combination of the above characteristics of $\varepsilon_{e p}$ corresponds to the flange prying-up phenomenon of T-stub, which was predicted during the designing and discovered during the tests, as shown in Figures 7 and 14. However, according the four subfigures of Figure 13, it is obvious that for a given $x$ and $\Delta_{1 s t,+}$, the $\varepsilon_{e p}$ calculated by IHM-S is different from that calculated by CHM-S, especially at the area near the intersection line of the web and flange. This observation indicates that IHM and CHM would give different results when they are used to predict the level of plastic development, especially in the area with large $\varepsilon_{e p}$.

4.2. Hysteresis Curve. The three force-displacement hysteresis curves obtained through IHM-S, CHM-S, and experiment are shown in Figures 15 and 16. It is observed that each of the two simulation curves can well capture the pinching effect of the experimental hysteresis curve. As a whole, each contour of the two predicted curves is consistent with that of the experimental curve; hence, it is inferred that the prediction model, whose configuration is stated in Section 3.2 in detail, can well simulate the friction and contact behavior of the really tested $\mathrm{T}$-stub connection under large deformations. However, in the later loading stages, there is a remarkable difference between the ultimate bearing capacities of the two FE models, which is attributed to the different hardening criteria defined by CHM and IHM. As can be observed in the plots, the ultimate bearing capacity calculated by CHM-S is more consistent with the experimental value than that calculated by IHM-S.

4.3. Skeleton Curve. There are several loops on the $P-\Delta$ curve in a single loading level, which belong to the entire hysteresis curve, and the skeleton curve is the one that 


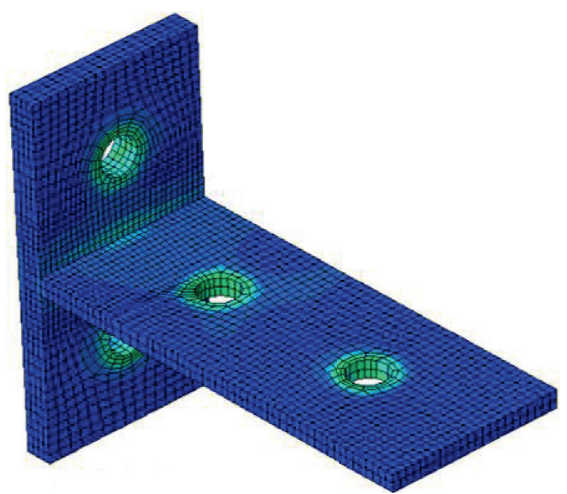

(a)

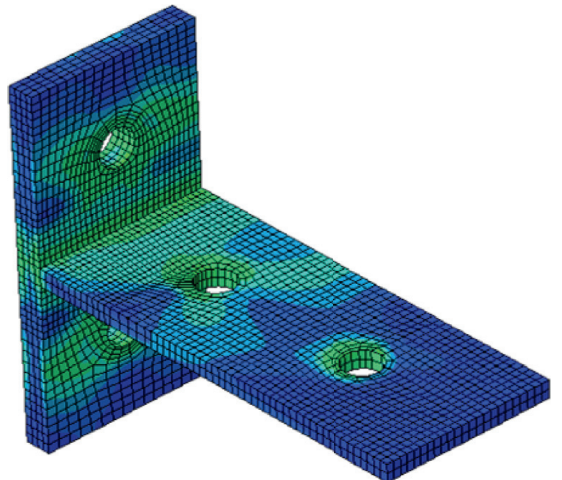

(d)

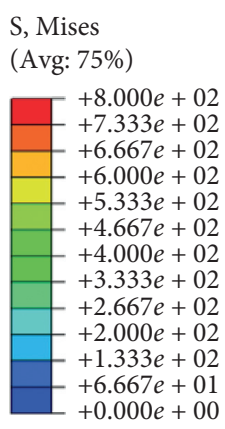

(b)

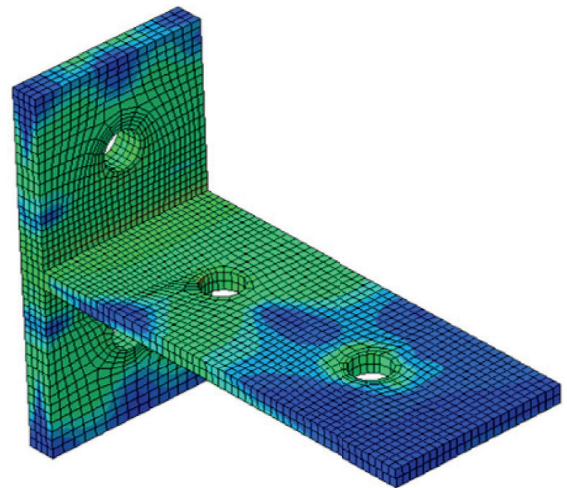

(e)

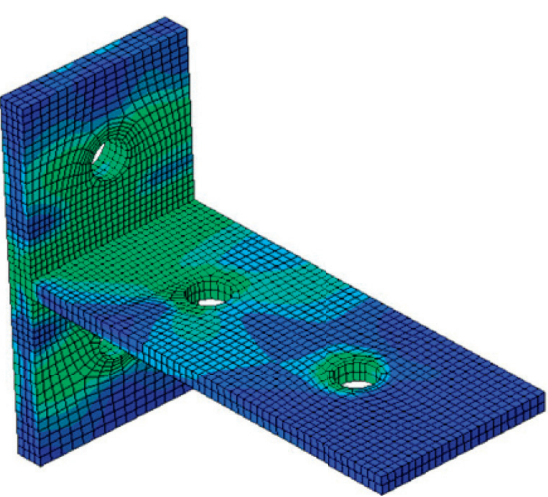

(c)

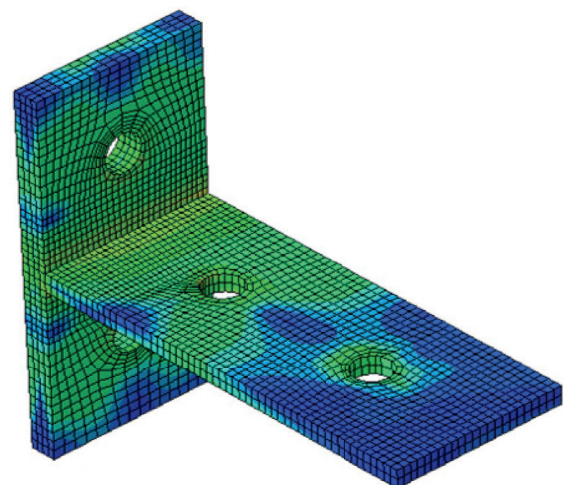

(f)

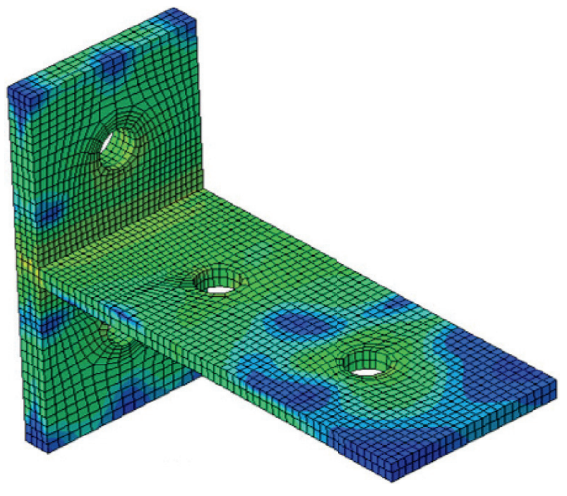

(g)

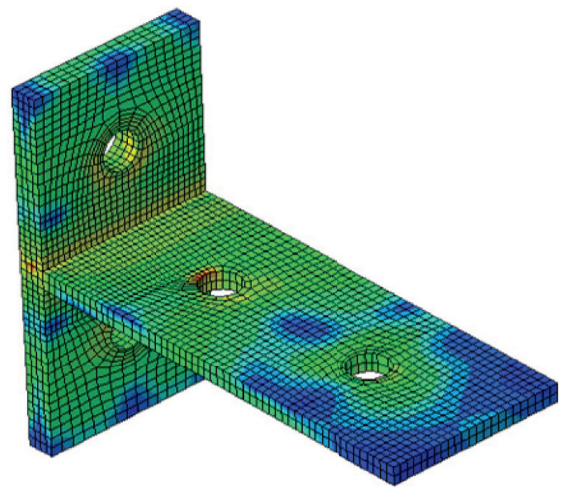

(h)

Figure 11: Mises stress $\sigma_{m i}$ contour plots for $T_{t}$ T-stub. The above contour plots are those obtained when the displacement is at the loading point $\Delta_{1 \text { st },+} \in \mathbf{d}_{\text {con }}=\{5,20,35,60\} ; \Delta_{\mathrm{I}}$ represents the IHM-S result, and $\Delta_{C}$ represents the CHM-S result. (a) $(L 1) \Delta_{\mathrm{I}}=5 \mathrm{~mm}$. (b) $(R 1) .(\mathrm{c})$ (L2) $\Delta_{\mathrm{I}}=20 \mathrm{~mm}$. (d) (R2) $\Delta_{\mathrm{C}}=20 \mathrm{~mm}$. (e) (L3) $\Delta_{\mathrm{I}}=35 \mathrm{~mm}$. (f) (R3) $\Delta_{\mathrm{C}}=35 \mathrm{~mm}$. (g) (L4) $\Delta_{\mathrm{I}}=60 \mathrm{~mm}$. (h) (R4) $\Delta_{\mathrm{C}}=60 \mathrm{~mm}$.

connects the reverse loading points of the first loop at each loading level. For a structure under study, the skeleton curve can reflect both the strength and stiffness, and it is the basis for determining the ductility of the structure and restoring the force model [31].

The skeleton curves of the T-stub connection obtained through IHM-S, CHM-S, and experiment are shown in Figure 17. From the figure, at least three inferences can be made. Firstly, it is obvious that the initially small segment of the skeleton curve obtained from CHM-S basically coincides with the same segment of that obtained from IHM-S when the elastic response of the two FE models dominates. Secondly, it is obvious that the two originally coincided segments branch as the displacement increases, more precisely, as the plastic deformation develops. Thirdly, the skeleton curve obtained from CHM-S coincides more with the experimental curve than that obtained from IHM-S.

There is also a need for numerical analysis of the degree of deviation of each of the two simulation skeleton curves from the experimental curve at different loading levels, 


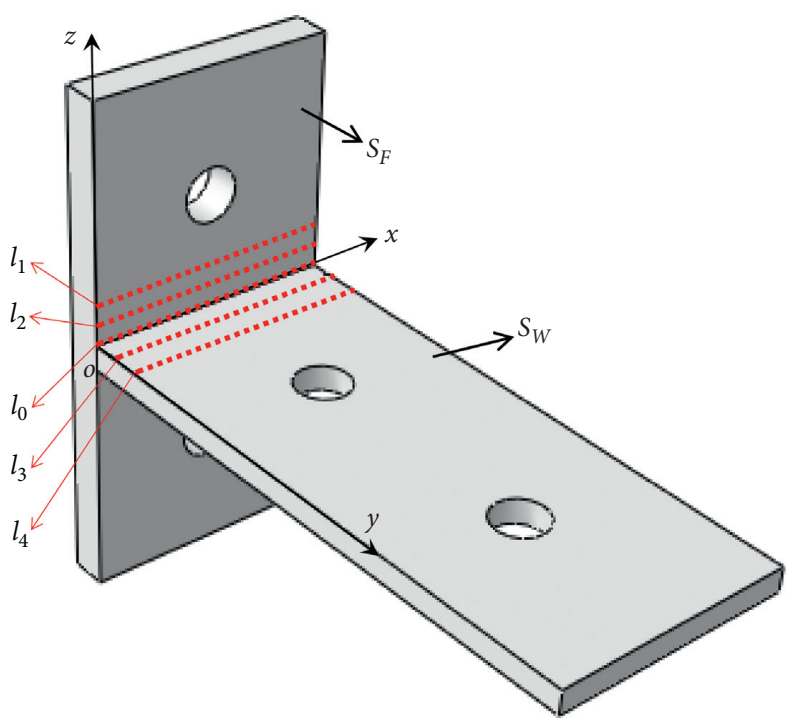

Figure 12: The typical paths of $T_{t}$.

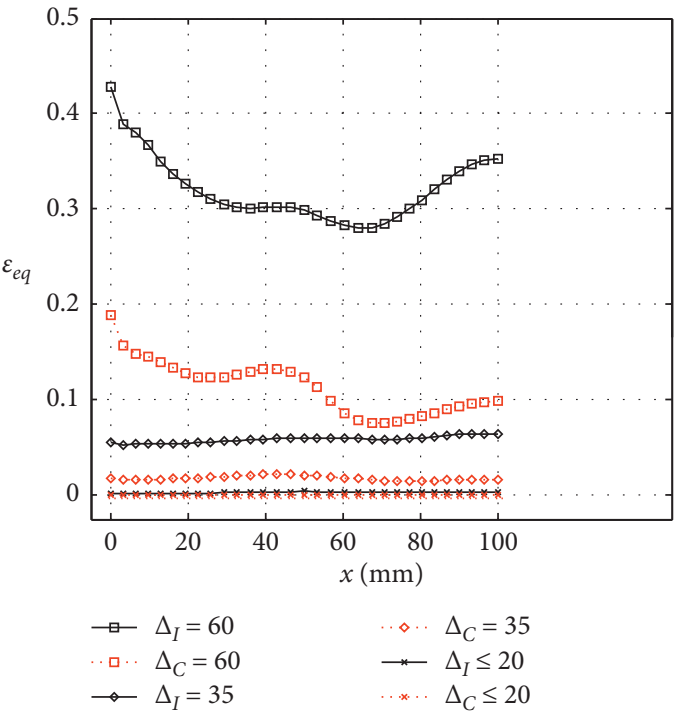

(a)

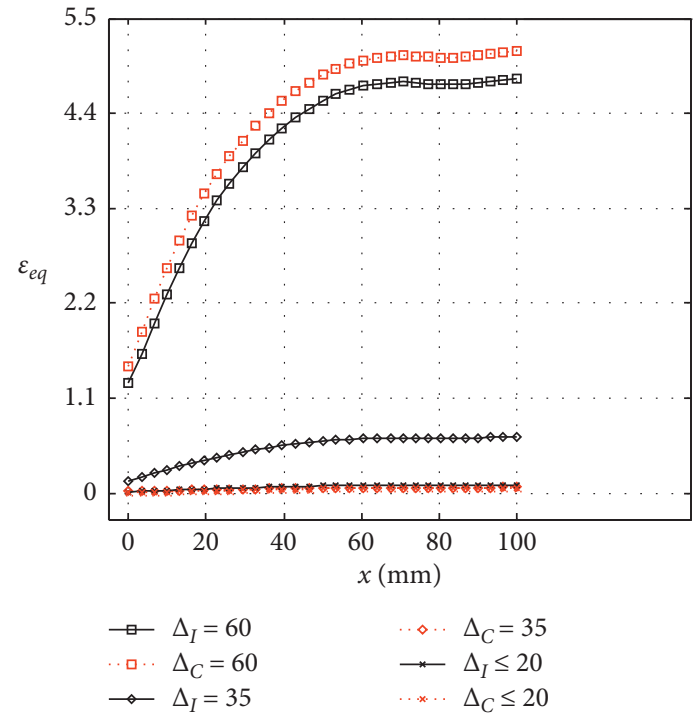

(b)

Figure 13: Continued. 


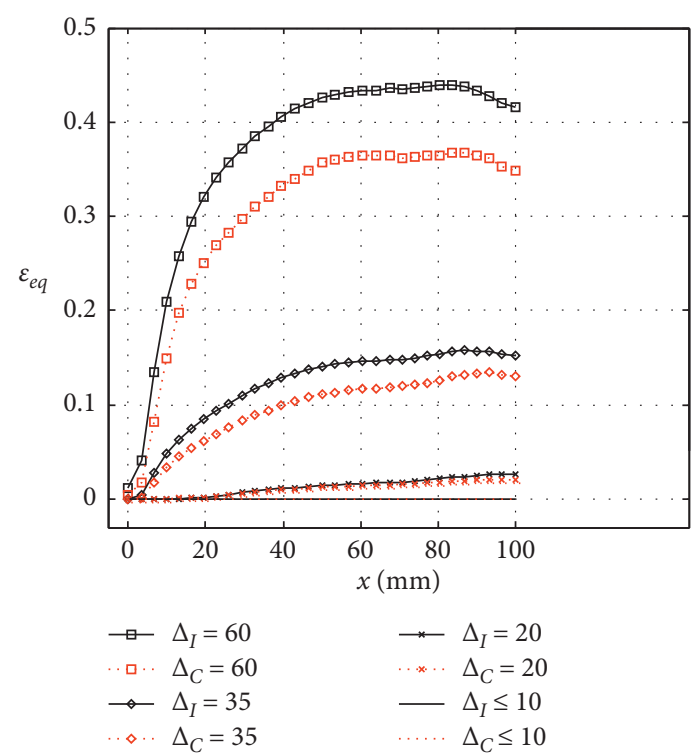

(c)

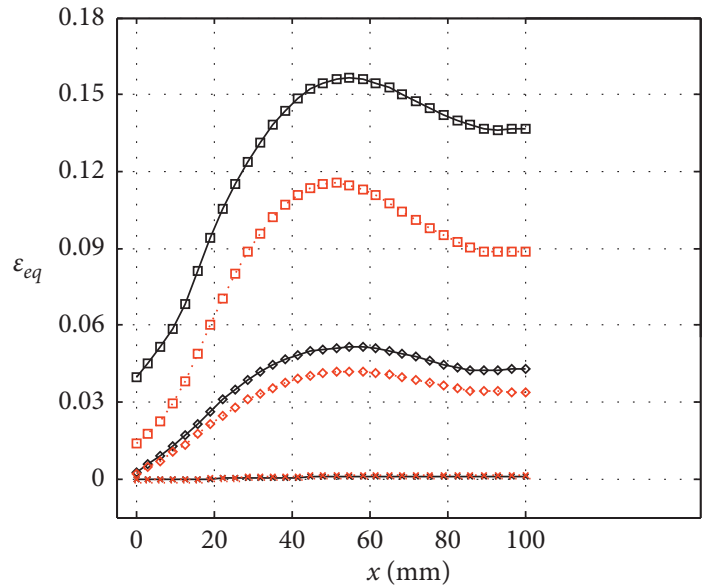

$$
\begin{aligned}
& \rightarrow \Delta_{I}=60 \quad \therefore \Delta \cdots \Delta_{C}=35 \\
& \text { … } \Delta_{C}=60 \quad \longrightarrow \Delta_{I} \leq 20 \\
& \rightarrow \Delta_{I}=35 \quad \cdots * \Delta_{C} \leq 20
\end{aligned}
$$

(d)

Figure 13: Equivalent strain $\varepsilon_{e p}$ at paths $l_{1}, l_{2}, l_{3}$, and $l_{4}$. (a) Path $l_{1}$. (b) Path $l_{2}$, (c) Path $l_{3}$, (d) Path $l_{4}$. The values without the unit in the legends indicate the displacement; $\varepsilon_{e p}$ is the value when the displacement at the loading point $\Delta$ first reached $d_{\text {con }} \in\{5,10,20,40,60\} \mathrm{mm} ; \Delta_{\mathbf{I}}$ represents the IHM-S result and $\Delta_{\mathrm{C}}$ represents the CHM-S result.

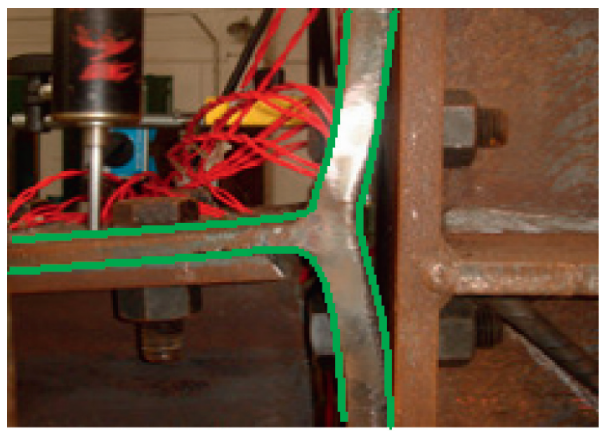

FIGURE 14: Flange prying-up phenomenon of T-stub.

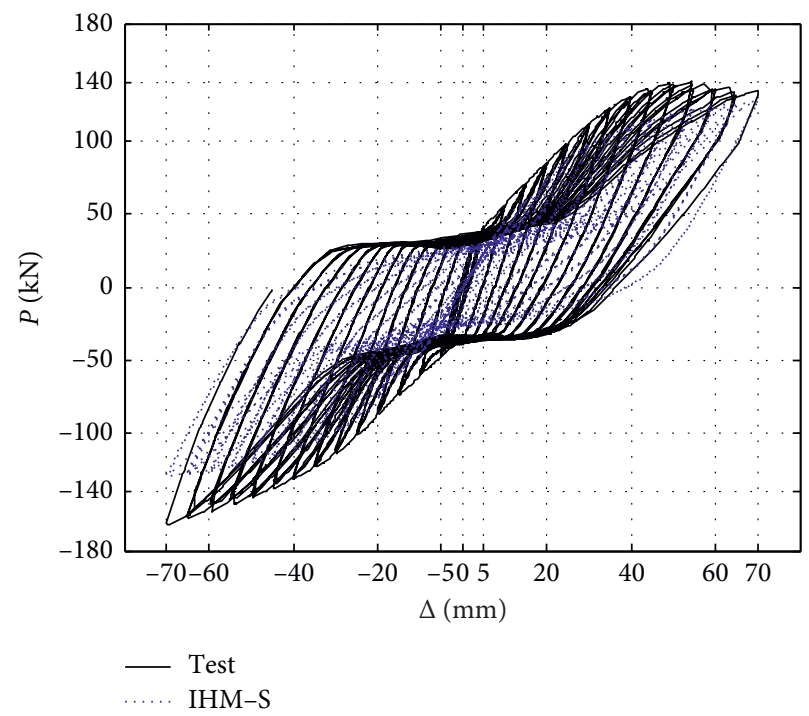

FIGURE 15: Comparison between the hysteresis curves from the experiment and that of IHM-S. 


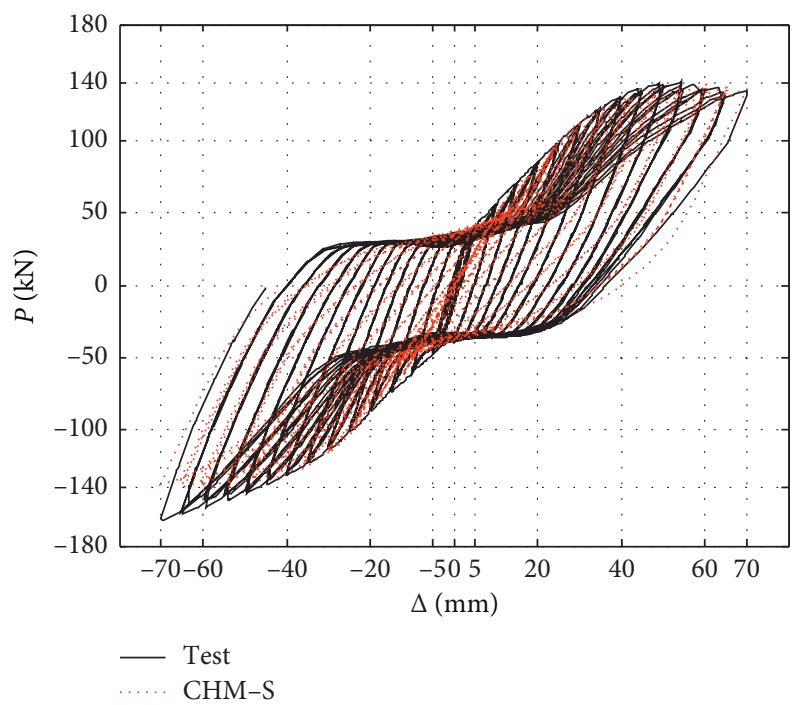

Figure 16: Comparison between the hysteresis curves from the experiment and that of CHM-S.

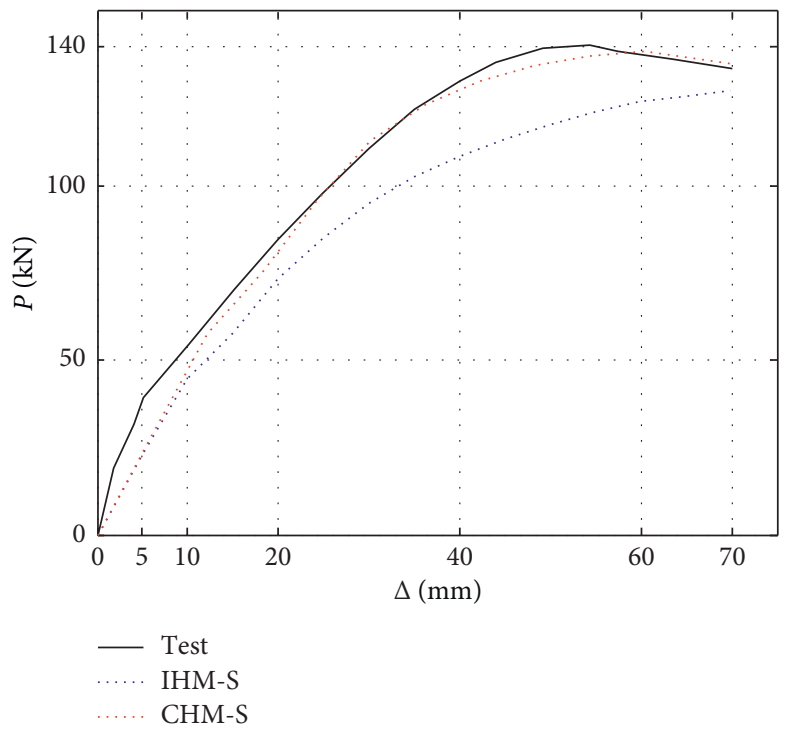

Figure 17: Comparison between the skeleton curves from the experiment and those obtained by simulation.

especially after the plastic deformation sets in. Because the stiffness of the T-stub connection is greatly influenced by the plasticity of the T-stub $[3,4]$, the dimensionless index $\beta_{\Delta} \triangleq\left(\left|\delta_{y}-\Delta_{y}\right| /\left|\Delta_{y}\right|\right)$ was constructed to make the comparison reasonable and facilitative, where $\Delta_{y}$ is the displacement of the loading point at the first appearance of the yield zone on $T_{t}, \delta_{\vec{y}}$ is the peak or valley displacement of a loading level when $T_{t}$ has yielded, and $\Delta_{y}$ and $\delta_{y}$ must have the same sign. For the T-stub connection discussed herein, it was found that the absolute value of $\Delta_{y}$ obtained from CHM-S is approximately equal to that of IHM-S based on the simulation data, and the estimated value, $\left|\Delta_{y}\right|=7.5 \mathrm{~mm}$, was used to analyze the degree of deviation aforementioned. Based on the above two preparative works, the positive peak reactive forces, $P_{p+}$, at the loading point in the first cycle of the loading levels when $d_{\text {con }}>\Delta_{y}$ are all shown in Table 4. As shown in the table, the three variables, $P_{t}, P_{\mathrm{I}}$, and $P_{\mathrm{C}}$, whose subscripts $p+$ are omitted, are the positive peak reactive forces obtained from the experiment, CHM-S, and IHM-S, respectively. The table also presents the comparative results of $P_{p+}$ from CHM-S and IHM-S with that from the experiment. Based on the data in Table 4, the results obtained from CHM-S are better than those from IHM-S considering their consistency with the experimental results. Also, considering the boundary shapes of the hysteresis curves shown in Figures 15 and 16, the same conclusion is drawn when the negative peak reactive forces, $P_{p^{-}}$, are compared. 
TABle 4: Comparison between some positive peak loading forces $P_{p+}$ and the comparisons between them.

\begin{tabular}{lcccccc}
\hline$\delta_{\vec{y}}(\mathrm{~mm})$ & $\beta_{\widetilde{\Delta}}$ & $P_{t}(\mathrm{kN})$ & $P_{\mathbf{I}}(\mathrm{kN})$ & $P_{\mathrm{C}}(\mathrm{kN})$ & $\left(\left|P_{\mathbf{I}}-P_{t}\right| / P_{t}\right) / \%$ & $\left(\left|P_{\mathrm{C}}-P_{t}\right| / P_{t}\right) / \%$ \\
\hline 10 & 0.33 & 54.5 & 44.5 & 47.5 & 18.4 & 14.6 \\
20 & 1.67 & 84.7 & 72.3 & 81.3 & 16.5 & 4.01 \\
40 & 4.33 & 129.8 & 108.4 & 127.5 & 9.75 & 1.77 \\
60 & 7.00 & 137.5 & 138.3 & 124.1 & 4.72 & 0.58 \\
70 & 8.12 & 133.5 & 127.2 & 135.9 & 1.80 \\
\hline
\end{tabular}

Note. The subscript, $p+$, which denotes a positive peak was omitted, and the subscripts $t$, I, and C, denote the results from the test, IHM-S, and CHM-S, respectively.

\section{Conclusion}

Accurate FE simulations of beam-column steel connections such as T-stub connection under a large cyclic plastic deformation is vital in making rational investigations of their plastic deformation capacity. A numerical FE model of a reported and extensively tested $\mathrm{T}$-stub connection was developed to study the predictive differences of the quasi-static behaviors caused by the selection of two constitutive models in the case of large cyclic plastic deformation. One of the models employed the isotropic hardening constitutive model (IHM), which has been widely used in previous studies on the plastic deformation capacity of T-stub connections. The other model is the Chaboche constitutive model, which has not been extensively employed for such studies. It can give a more accurate model of material behaviors under cyclic plastic conditions. The parameters of the two constitutive models were calibrated through a uniaxial tensile test and three cyclic tension-compression tests. The steel specimens for the calibration of constitutive models were fabricated from the same structural steel used to manufacture the T-stub connection. Both FE models that adopted IHM and CHM were simulated under the loading scheme of the really tested connection. The main conclusions are drawn thus:

(1) .The choice of IHM or CHM has little influence on some qualitative indexes, such as the distribution laws of Mises stress and equivalent plastic strain, $\varepsilon_{e p}$, in the T-stub, as well as the pinching effect of the hysteretic curve. However, it has a significant influence on such quantitative indexes as the values of $\varepsilon_{e p}$ in the T-stub and the reacting force at the loading point when a controlled displacement with the same history occurs.

(2) The simulation results of the two FE models with different constitutive models are similar and in good agreement with the experimental results when the cumulative plastic deformation is small. However, the results obtained from the model using CHM are in better agreement with the experimental results than that obtained from the model using IHM when the plastic deformation is large.

For further studies, CHM can be adopted to perform critical FE simulations on the cyclic plastic behavior of T-stubs as well as on the cyclic plastic behavior of the overall T-stub connections.

\section{Abbreviations}

IHM: Isotropic-hardening constitutive model

CHM: Chaboche constitutive model

IHM-S: The simulation work on the FE model adopted $\mathrm{CHM}$

CHM- The simulation work on the FE model adopted S: $\quad$ IHM

\section{Nomenclature}

$T_{t}: \quad$ The top T-stub in the FE model of T-stub connection

$l_{i}: \quad$ The $i$ th path in $T_{t}$

$t$, I, C: denoted by test, IHM-S, and CHM-S

${ }_{ \pm}$: $\quad$ Positive $(+)$ or negative $(-)$ at the loading point

$\because \quad$ Rate form

E: $\quad$ Material elastic modulus

$\nu$ : Poisson's ratio

$\varepsilon: \quad$ Strain scalar

$\varepsilon_{p}$, Plastic strain scalar and equivalent plastic strain

$\varepsilon_{e p}$

$\sigma, \sigma: \quad$ Stress tensor and stress scalar

$\alpha$ : Back-stress tensor

$s_{y, 0}: \quad$ Initial yield stress scalar

$k$ : Hardening function or value of a hardening function

$\sigma_{m i}: \quad$ Mises stress

$\Delta: \quad$ Vertical displacement at the loading point

$\Delta_{1 s t,+}$ : The maximum positive $\Delta$ in a single loading level

$\Delta_{y}: \quad$ The $\Delta$ when a yield zone firstly appears in $T_{\mathrm{t}}$

$\delta_{\vec{y}}$ : The peak $\Delta$ in a single loading level after $\Delta_{y}$ appears

$P: \quad$ Vertical load at the loading point

$P_{p}, P_{u}$ : The peak $P$ in a single loading level, the ultimate $P$ in all loading levels

$d_{\text {con }}$ : Absolute value of controlled displacement at the loading point

$\mathbf{d}_{\text {con }}$ : Sequence of some $\mathbf{d}_{\text {con }}$

$d_{i}$ : The $d_{\text {con }}$ during the $i^{\text {th }}$ loading level

$\beta_{\Delta}$ : $\quad$ The index of T-stub connection plastic development.

\section{Data Availability}

All data and models used during the study are available from the corresponding author upon request (Zeshen Li, Ph.D.; e-mail: lizeshen@163.com).

\section{Conflicts of Interest}

The authors declare that they have no conflicts of interest. 


\section{Acknowledgments}

This work was supported by the Construction and Scientific Research Projects of Zhejiang Province (no. 2019K016) and Systematic Project of Guangxi Key Laboratory of Disaster Prevention and Structural Safety (2019ZDX018). This work was in part supported by the Zhejiang Construction Investment Group Co., Ltd.

\section{References}

[1] S. A. Mahin, "Lessons from damage to steel buildings during the Northridge earthquake," Engineering Structures, vol. 20, no. 4-6, pp. 261-270, 1998.

[2] M. Nakashima, C. W. Roeder, and Y. Maruoka, "Steel moment frames for earthquakes in United States and Japan," Journal of Structural Engineering, vol. 126, no. 8, pp. 861-868, 2000.

[3] V. Saberi, M. Gerami, and A. Kheyroddin, "Comparison of bolted end plate and T-stub connection sensitivity to component thickness," Journal of Constructional Steel Research, vol. 98, pp. 134-145, 2014.

[4] J. A. Swanson and R. T. Leon, "Bolted steel connections: tests on T-stub components," Journal of Structural Engineering, vol. 126, no. 1, pp. 50-56, 2000.

[5] E. P. Popov and S. M. Takhirov, "Bolted large seismic steel beam-to-column connections Part 1: experimental study," Engineering Structures, vol. 24, no. 12, pp. 1523-1534, 2002.

[6] S. M. Takhirov and E. P. Popov, "Bolted large seismic steel beam-to-column connections Part 2: numerical nonlinear analysis," Engineering Structures, vol. 24, no. 12, pp. 1535-1545, 2002.

[7] Z. Kong and S.-E. Kim, "Numerical estimation for initial stiffness and ultimate moment of T-stub connections," Journal of Constructional Steel Research, vol. 141, pp. 118-131, 2018.

[8] A. N. Sherbourne and M. R. Bahaari, "3D simulation of bolted connections to unstiffened columns-I. T-stub connections," Journal of Constructional Steel Research, vol. 40, no. 3, pp. 169-187, 1996.

[9] R. Tartaglia, M. D’Aniello, and M. Zimbru, "Experimental and numerical study on the T-Stub behaviour with preloaded bolts under large deformations," Structures, vol. 27, pp. 2137-2155, 2020.

[10] M. D’Aniello, D. Cassiano, and R. Landolfo, "Simplified criteria for finite element modelling of European preloadable bolts," Steel \& Composite Structures, vol. 24, no. 6, pp. 643658, 2017.

[11] A. C. Faralli, P. J. Tan, M. Latour, and G. Rizzano, "Finite element analysis of bolted T-stubs undergoing large displacement: a preliminary study," The Open Construction and Building Technology Journal, vol. 12, no. 1, pp. 170-176, 2018.

[12] E. G. Hantouche, A. R. Kukreti, G. A. Rassati, and J. A. Swanson, "Modified stiffness model for thick flange in built-up T-stub connections," Journal of Constructional Steel Research, vol. 81, pp. 76-85, 2013.

[13] A. M. G. Coelho, L. S. D. Silva, and F. S. K. Bijlaard, "Finiteelement modeling of the nonlinear behavior of bolted T-stub connections," Journal of Structural Engineering, vol. 132, no. 6, pp. 918-928, 2006.

[14] C. J. Gantes and M. E. Lemonis, "Influence of equivalent bolt length in finite element modeling of T-stub steel connections," Computers \& Structures, vol. 81, no. 8-11, pp. 595-604, 2003.
[15] G. A. Anwar, F. Dinu, and M. Ahmed, "Numerical study on ultimate deformation and resistance capacity of bolted T-stub connection," International Journal of Steel Structures, vol. 19, no. 3, pp. 970-977, 2018.

[16] I. Both, R. Zaharia, I. Mrginean, C. Neagu, and D. Dubina, "Tstubs response to extreme loading," in The International Colloquium on Stability and Ductility of Steel StructuresCzech Technical University in Prague, Prague, Czech Republic, 2016.

[17] O. C. Zienkiewicz, R. L. Taylor, and D. D. Fox, The Finite Element Method for Solid and Structural Mechanics, Elsevier/ Butterworth, Heinemann, Amsterdam, Netherlands, 7th edition, 2014.

[18] W. F. Chen and A. F. Saleeb, Elasticity and Plasticity, Architecture and Building Press, Beijing, China, 2004.

[19] Simulia, Abaqus 6.14 Theory Guide, Simulia, Johnston, RI, USA, 2014.

[20] X. C. Wang and L. M. Chang, "Exact integration of constitutive equations of kinematic hardening materials and its extended applications," Acta Mech Sinica, vol. 3, no. 2, pp. 139-149, 1987.

[21] J. L. Chaboche, "A review of some plasticity and viscoplasticity constitutive theories," International Journal of Plasticity, vol. 24, no. 10, pp. 1642-1693, 2008.

[22] H. Badnava, H. R. Farhoudi, K. F. Nejad, and S. M. Pezeshki, "Ratcheting behavior of cylindrical pipes based on the Chaboche kinematic hardening rule," Journal of Mechanical Science and Technology, vol. 26, no. 10, pp. 3073-3079, 2012.

[23] A. Shojaei, M. R. Eslami, and H. Mahbadi, "Cyclic loading of beams based on the Chaboche model," International Journal of Mechanics and Materials in Design, vol. 6, no. 3, pp. 217228, 2010

[24] E. Mancini, D. Isidori, M. Sasso, C. Cristalli, D. Amodio, and S. Lenci, "Characterization of the cyclic-plastic behaviour of flexible structures by applying the Chaboche model," Archives of Civil and Mechanical Engineering, vol. 17, no. 4, pp. 761775, 2017.

[25] M. Rezaiee-Pajand and S. Sinaie, "On the calibration of the Chaboche hardening model and a modified hardening rule for uniaxial ratcheting prediction," International Journal of Solids and Structures, vol. 46, no. 16, pp. 3009-3017, 2009.

[26] Z. S. Li, X. M. Li, X. W. Zheng, and K. S. Zhang, "Experimental study and numerical investigation on hysteretic behavior of T-stub semi-rigid beam-to-column connections," Journal of Building Structures, vol. 35, no. 7, pp. 61-68, 2014.

[27] J. J. Jiang, J. Li, and W. L. Jin, The Advanced Design of Concrete Structures, Architecture and Building Press, Beijing, China, 2007.

[28] T. Belytschko, W. K. Liu, B. Moran, and K. Elkhodary, Nonlinear Finite Elements for Continua and Structures, Tsinghua University Press, Beijing, China, 2016.

[29] O. T. Bruhns, "The Prandtl-Reuss equations revisited," ZAMM-Journal of Applied Mathematics and Mechanics, vol. 94, no. 3, pp. 187-202, 2014.

[30] Simulia, ABAQUS 6.14 Analysis Users Guide (Volume III), Simulia, Johnston, RI, USA, 2014.

[31] Hunan University, Taiyuan University of Technology, and Fuzhou University, Building Structure Test, Architecture and Building Press, Beijing, China, 2nd edition, 1991. 